\title{
Políticas de fomento à leitura e ações para a participação da pessoa com deficiência visual em Uberaba-MG
}

\author{
Dulceana Pereira* \\ Luciana Beatriz de Oliveira Bar Carvalho**
}

\section{Resumo}

Este artigo se trata de uma pesquisa documental e bibliográfica, cuja proposta foi avaliar o impacto das políticas de fomento à leitura, o Programa Nacional de Incentivo à Leitura (PROLER) e a inclusão de alunos com deficiência visual nas unidades de ensino do município de Uberaba-MG a partir da busca e identificação de projetos relacionados ao PROLER em Projetos Políticos Pedagógicos (PPP) de dez escolas municipais de Uberaba e conhecer como se dá a participação das pessoas com deficiência visual nessas ações de incentivo à leitura. Entende-se que a compreensão da Inclusáo precisa ser abordada como política pública, devendo nortear a construçáo e a compreensáo histórica de seus avanços e entraves. Autores como Jambeiro, Borges e Barros (2006), Libâneo (2001), Mantoan (2006) e Vasconcellos (2000) foram utilizados como referencial teórico deste artigo. Como resultados, foram encontradas açóes isoladas, ora sobre a inclusão por meio das tecnologias para o deficiente visual, ora sobre práticas de leitura por meio de experiências exitosas em pontos isolados. Os PPPs pesquisados mostraram açóes de leitura sem a participação direta das açóes do comitê Vale do Rio Grande, sediado por Uberaba. Ressalta-se a necessidade de maiores estudos para que a população, os gestores e demais órgáos públicos possam respeitar as diferenças e compreender as reais necessidades da pessoa com deficiência, garantindo assim sua autonomia nos diversos espaços da sociedade.

Palavras-chave: Deficiência visual; PROLER; Projeto Político Pedagógico.

* Doutoranda em Educação pela Universidade de Uberaba, Uberaba, Minas Gerais, Brasil.

** Professora doutora da Universidade de Uberaba, Uberaba, Minas Gerais, Brasil. 


\section{Reading support policies and actions for the participation of visually impaired people in Uberaba-MG}

\section{Abstract}

This article is a documentary and bibliographical research, whose purpose was to evaluate the impact of reading support policies, the National Reading Incentive Program (PROLER) and the inclusion of students with visual impairment in educational units in the city of Uberaba-MG by the search and identification of PROLER related projects in Political Pedagogical Projects (PPP) of ten municipal schools in Uberaba and know how the participation of the visually impaired people in these reading incentive actions works. It is noticed that the understanding of inclusion needs to be addressed as a public policy, guiding the construction and historical understanding of its progress and obstacles. Authors like Jambeiro, Borges and Barros (2006), Libâneo (2001), Mantoan (2006) and Vasconcellos (2000) were used as the theoretical framework of this article. As a result, isolated actions were found, sometimes about the inclusion by technologies for the visually impaired, sometimes about successful experiences of reading practice in isolated spots. The surveyed PPP showed reading actions without the direct participation of the activities of the Rio Grande Valley Committee, headquartered in Uberaba. It emphasizes the need for further studies for the population, managers and other public agencies to respect differences and understand the real needs of the impaired people, ensuring their autonomy in all areas of society.

Keywords: Visual impairment; PROLER; Political Pedagogical Project.

\section{Introdução}

Desde o nascimento, o ser humano é estimulado a observar o mundo ao seu redor. De todos os sentidos, a visão é a mais utilizada, pois, por meio dela, pode ser observado o contorno, a forma e a cor dos objetos, a expressão da face e paisagens. Aliada a outros sentidos, a visão permite reconhecer lugares, imitar gestos e associar diversas aprendizagens que irăo perpetuar por toda a vida, exercendo uma atividade exploratória circunscrita a um espaço delimitado. (SÁ; CAMPOS; SILVA, 2007).

Segundo o Ministério da Educação (MEC, 2007), a cegueira é uma alteração grave ou total de funçôes elementares da visão, afetando a capacidade de informaçôes visuais, como percepção de cor, tamanho, distância, forma, posição ou movimento. A cegueira pode ser congênita (desde o nascimento) ou adquirida após o nascimento devido a causas orgânicas ou acidentais, condiçôes que exigem intervençôes diferentes, pois um indivíduo que nasce cego precisa desenvolver funçôes que não dependerão da função visual, já os que adquiriram a cegueira poderão ter uma referência visual dos objetos, utilizando sua memória visual. A baixa visão, por sua vez, acontece quando o indivíduo apresenta uma grave dificuldade visual que não pode ser corrigida com o uso dos óculos. 
A deficiência visual (DV) talvez seja a que mais vem conquistando seu espaço, no sentido de acesso com autonomia e defesa de direitos. Reconhece-se que há um longo caminho para percorrer, pois ainda se encontram barreiras difíceis de transpor, seja por entraves políticos, econômicos, sociais e familiares. Sendo assim, quanto mais o tema for abordado, maiores serão as chances de a teoria ser esclarecida e, assim, o que são incertezas poderão se tornar desafios e atitudes proativas com soluções viáveis para a participação efetiva e autônoma da pessoa com deficiência visual.

A inclusão de pessoas com deficiência no ambiente escolar é um tema que instiga aprofundamento nas concepçôes e diretrizes que envolvem a temática. Discutir sobre inclusão é abrir espaço para reflexôes sobre a finalidade da avaliação escolar, a prática pedagógica, além de conceitos de homem e de mundo em prol de uma sociedade mais igualitária e democrática.

$\mathrm{O}$ acesso à educação das pessoas com necessidades educacionais especiais foi lentamente alcançado à medida que foram ampliando as oportunidades educativas para a populaçáo em geral. Leitáo e Fernandes (2011) destacam que, no Brasil, o marco legal da oficialização dos princípios inclusivos na educação ocorreu com a Constituição Federal de 1988 (BRASIL, 1988) que retrata que a efetivação do dever do Estado com a educação se efetiva ao garantir atendimento educacional especializado às pessoas com deficiência, preferencialmente ofertado na rede regular de ensino. A inclusão tem como referência o respeito às diferenças e compreende que todo o contexto social e educacional deve estar preparado para receber a pessoa com deficiência.

É importante ressaltar que, mesmo estando amparada por leis e decretos, a participação da pessoa com deficiência nos segmentos sociais ainda deixa a desejar. As mudanças não ocorrem rapidamente, uma vez que estas implicam questôes de ordem política, científica, pedagógica, administrativa e financeira. Godoffredo (2007) destaca que a Educaçáo Especial deve centrar suas açóes na qualidade da oferta, na equidade de oportunidades e na permanente capacitaçáo de todos os profissionais responsáveis pelo processo educacional dos alunos com necessidades educacionais especiais.

Mesmo reconhecendo que não se pode definir o que um deficiente consegue e o que não consegue realizar, é necessário oferecer-lhe o direito de participar ativamente dos processos de aprendizagem, seja na escola, em casa, no trabalho e/ou no lazer. Para tanto, entende-se que a essência dos pressupostos sobre inclusão escolar está no respeito às diferenças. Percebe-se um crescente movimento das pessoas com deficiência na capacidade de empoderamento de direitos e em busca de melhores condiçóes, apesar de ainda faltarem políticas públicas que possam garantir esses direitos. As discussóes sobre que rumos tomar a respeito das necessidades especiais têm sentido se houver a participação do deficiente, pois ele sabe o que é melhor para si.

Carvalho (2004) explica que mais importante do que discutir sobre como incluir, é preciso ter clareza de que a ideia da inclusão educacional pressupôe a melhoria da resposta educativa da escola para todos em qualquer oferta educacional. O maior desafio é conquistar uma escola aberta às diferenças, reconhecendo sua necessidade 
ao processo de construção de uma escola de qualidade. A criança com deficiência precisa vivenciar as mesmas experiências que as demais e, para isso, a escola deve ser rica em estímulos e vivências. As barreiras são mais atitudinais do que físicas e tecnológicas, especialmente sobre a falta de recursos e preparo de profissionais. A escola precisa avançar e se aperfeiçoar em suas propostas pedagógicas, garantindo nova postura dos educadores, aulas e espaços acessíveis a todos (MANTOAN, 2006).

Este trabalho enfatizará as pessoas com deficiência visual pela necessidade de discussão sobre práticas de ensino, políticas públicas e meios que garantam melhores condições de permanência e participação nos sistemas educacionais.

Entre os meios que facilitam a vida de quem enxerga ou não estão as tecnologias, presentes no cotidiano nas mais diversas situaçôes e tão incorporadas nas atividades que se torna difícil apontá-las. Para as pessoas com deficiência, as Tecnologias Assistivas (TA) adquirem relevância à medida que permitem executar tarefas cotidianas com autonomia, além de ampliar habilidades funcionais dessas pessoas, promovendo a inclusão (BERSCH; TONOLLI, 2006). Muitas TAs necessárias à inclusão social de pessoas cegas ainda têm custos elevados, dificultando o acesso ao usuário comum (NUNES, 2007) e prejudicando o processo de inclusão, já que as TAs constituem a principal contribuição da ciência e da tecnologia a esse processo (FERRARI, 2008).

O Braile é considerado uma tecnologia assistiva, sendo o sistema de leitura e escrita tátil mais adotado no mundo (GRAFIA BRAILLE PARA A LÍNGUA PORTUGUESA, 2006). Assim como o braile vem ganhando espaço para ser mais acessível aos seus usuários, a leitura no Brasil também passa por esse processo. Depreende-se que a leitura foi mais direcionada a uma minoria, a partir do que se percebe a necessidade de democratização da leitura por meio de políticas de acesso, o que precisa superar obstáculos cujas origens estáo em fatores que causam desigualdade social. O hábito da leitura permeia essa questâo, mais uma vez reforçando a necessidade de investir na educaçáo em busca de desenvolvimento, redução das desigualdades e promoção do bem de todos (JAMBEIRO; BORGES; BARROS, 2006).

Foram criadas propostas para incentivar a leitura no Brasil, entre elas a Lei $\mathrm{n}^{\circ} 10.753 / 2003$ (BRASIL, 2003), que instituiu a Política Nacional do Livro, que autoriza o Poder Executivo a criar projetos de incentivo à leitura e acesso ao livro. Outra proposta é o Programa Nacional de Incentivo à Leitura (PROLER) que, de alguma forma, está ativo no País desde 1992. Ele ainda não pode ser considerado uma política pública por não haver uma formalidade nacional, e a adesão a ele é feita livremente, não havendo obrigatoriedade. Há também o Plano Nacional do Livro e da Leitura (PNLL), que contempla diretrizes para as pessoas com deficiências, ainda pouco reconhecidas na sociedade e que têm direito a acessar materiais de leitura (BRASIL, 2006).

Voltando às atençóes ao contexto local do presente artigo, vale um olhar para conhecer as influências que impulsionaram a criação de um programa de leitura que perdura até hoje, assim como analisar como suas açóes são realizadas na regiáo. $\mathrm{O}$ Plano de Gestão da Prefeitura Municipal de Uberaba para a Gestão 2014-2016 di- 
vidiu suas ações em cinco programas, explanados em subprogramas, projetos e ações educativas. Com a nova gestão municipal em 2014, açôes que visavam à melhoria da educação, do acesso e da permanência dos educandos na escola foram reorganizadas pela equipe da Secretaria Municipal de Educação e Cultura (SEMEC), ficando o PROLER e o Seminário de Educaçáo Inclusiva juntamente organizados e com o objetivo de apoiar a formaçáo de gestores e educadores e transformar os sistemas educacionais em setores inclusivos.

Um dos meios que as escolas têm de organizar sua conduta educacional é pelo Projeto Político Pedagógico (PPP), instrumento teórico-metodológico que expóe objetivos, tipo de organização, forma de implementação e avaliação da escola (VEIGA, 1998). Ele se propóe a ressignificar os agentes do contexto escolar e organizá-lo em um ambiente seguro de aprendizagem, buscando enfrentar os desafios cotidianos dessa instituição (VASCONCELLOS, 2000).

A Lei de Diretrizes e Bases da Educação Nacional - Lei 9394/96 (BRASIL, 1996) exige a elaboração do PPP, que deve estar em consonância com o Plano Municipal Decenal de Educação e Plano de Gestáo da Educação Municipal. Segundo essa lei, os estabelecimentos de ensino devem elaborar e executar sua proposta pedagógica, respeitando normas comuns e as de seu próprio sistema de ensino, indicando que a escola deve refletir sobre sua intencionalidade educativa, tornando o PPP como objeto prioritário de estudo e discussão no campo educacional.

Sua prática contribui para afirmar a identidade da escola como espaço necessário à construção de conhecimentos e de cidadania. A função de um Projeto Pedagógico se consolida quando ajuda a resolver problemas e consegue transformar a prática, minimizando conflitos e dificuldades enfrentadas no cotidiano escolar (VASCONCELLOS, 2000). O PPP deve expressar a reflexão e o trabalho realizado em conjunto por todos os profissionais da comunidade escolar, no sentido de atender às diretrizes do sistema nacional de educação, às necessidades locais e específicas da clientela da escola (LIBÂNEO, 2001).

O presente artigo se trata de uma pesquisa documental e bibliográfica, cujo objetivo é avaliar o impacto das políticas de fomento à leitura, o PROLER e a inclusão de alunos com deficiência visual nas unidades de ensino do município por meio da análise de Projetos Político Pedagógicos de dez unidades municipais de Ensino Fundamental de Uberaba. Este trabalho faz parte de um projeto maior intitulado "As Políticas Públicas de Incentivo à Leitura: uma (re)leitura do Programa Nacional de Incentivo à Leitura (PROLER) e suas implicaçóes no IDEB no Município de Uberaba-MG". 


\section{Resultados e discussão}

\section{Ações do projeto político pegagógico das escolas de Uberaba}

Serão apresentadas as escolas selecionadas para a identificação de açôes que favoreçam a participação do deficiente visual no município de Uberaba. Para a escolha das escolas, utilizou-se como critério a nota do Índice de Desenvolvimento da Educação Básica (IDEB) de 2015. A amostra selecionada foi composta por cinco escolas que alcançaram melhor desempenho e cinco que tiveram o pior desempenho, a fim de ter imparcialidade e das quais se coletou o PPP. Ainda como critério da pesquisa, a escola selecionada deveria ter alunos com deficiência visual. Das dez escolas selecionadas, nove puderam ser analisadas porque uma não entregou o documento para a Secretaria de Educação, impedindo a análise. A fim de evitar identificação, as escolas serão mencionadas por siglas, conforme o quadro abaixo.

\begin{tabular}{|c|c|c|c|c|c|}
\hline \multicolumn{6}{|c|}{ UNIDADES MUNICIPAIS DE ENSINO PESQUISADAS } \\
\hline ESCOLAS & \multicolumn{5}{|c|}{ CRITÉRIOS DE ESCOLHA - REFERÊNCIA 2014} \\
\hline $\begin{array}{l}\text { MAIOR } \\
\text { IDEB }\end{array}$ & LOCALIZAÇĀO & $\begin{array}{c}\mathrm{N}^{\circ} \mathrm{DE} \\
\text { ALUNOS }\end{array}$ & $\begin{array}{c}\text { ALUNOS COM } \\
\text { DEFICIÊNCIA } \\
\text { VISUAL }\end{array}$ & IDEB & $\begin{array}{c}\text { PROJETO } \\
\text { POLÍ́TICO } \\
\text { PEDAGÓGICO }\end{array}$ \\
\hline $1 \mathrm{~A}-\mathrm{FE}$ & URBANA & 1106 & SIM & 6.6 & SIM \\
\hline $2 \mathrm{~A}-\mathrm{U}$ & URBANA & 1285 & SIM & 6.4 & SIM \\
\hline $3 \mathrm{~A}-\mathrm{MMG}$ & URBANA & 455 & SIM & 6.4 & SIM \\
\hline $4 \mathrm{~A}-\mathrm{SC}$ & URBANA & 755 & SIM & 6.1 & SIM \\
\hline $5 \mathrm{~A}-\mathrm{SM}$ & URBANA & 805 & SIM & 6.0 & SIM \\
\hline $\begin{array}{l}\text { MENOR } \\
\text { IDEB }\end{array}$ & LOCALIZAÇĀO & $\begin{array}{c}\mathrm{N}^{\circ} \mathrm{DE} \\
\text { ALUNOS }\end{array}$ & $\begin{array}{c}\text { ALUNOS COM } \\
\text { DEFICIÊNCIA } \\
\text { VISUAL } \\
\end{array}$ & IDEB & $\begin{array}{c}\text { PROJETO } \\
\text { POLÍTICO } \\
\text { PEDAGÓGICO }\end{array}$ \\
\hline $2 \mathrm{~B}-\mathrm{ELB}$ & URBANA & 352 & SIM & 4.1 & SIM \\
\hline $3 \mathrm{~B}-\mathrm{VAT}$ & URBANA & 925 & SIM & 4.4 & SIM \\
\hline $4 \mathrm{~B}-\mathrm{TM}$ & RURAL & 411 & SIM & 4.5 & SIM \\
\hline $5 B-M L$ & RURAL & 288 & SIM & 4.6 & SIM \\
\hline
\end{tabular}

Quadro elaborado pela autora.

Conforme se observa no quadro, as escolas com maior IDEB foram identificadas com a letra $A$, enquanto as que obtiveram menor IDEB foram denominadas com a letra B. A escola $1 \mathrm{~A}$ alcançou a maior pontuação e apresenta um número menor de alunos que a escola $2 \mathrm{~A}$. Já entre as que apresentaram a pior pontuação, verifica-se que as escolas $\mathrm{B}$ têm um número de alunos inferior e estão localizadas na periferia do município e na zona rural. O próprio documento dessas escolas relata que o fato de os alunos morarem em extensóes espaçadas dificulta a presença dos pais, o que reflete na falta de acompanhamento das atividades acadêmicas e numa possível relação com o baixo desempenho dos educandos. Apesar das informaçóes do quadro, não é possí- 
vel concluir que a quantidade de alunos e a localização da escola influenciam negativa ou positivamente na pontuação alcançada. Pela análise dos PPPs percebe-se que há muitos projetos semelhantes entre as escolas e que algumas desenvolvem açóes que deveriam ser divulgadas.

A seguir, seguem os projetos de leitura e inclusão escolar identificados nos projetos pedagógicos das escolas selecionadas.

\section{Escola $1 \mathrm{~A}-\mathrm{FE}$}

A escola tem um acervo bibliográfico insuficiente e desatualizado. A demanda de empréstimos é grande, assim como o número de alunos, não correspondendo aos títulos oferecidos. Quanto ao hábito de leitura, 51 alunos responderam que "sempre" leem, 88 alunos, "às vezes", e 30 alunos responderam "raramente".

A maioria dos professores indicou que a escola identifica desde o início do ano letivo as dificuldades de aprendizagem dos alunos e toma providências ( 25 responderam sim, sete responderam parcialmente e um respondeu não).

Sobre o PPP, 20 professores acreditam que a escola tem alcançado as metas definidas nos documentos, 12 professores julgam que atingem "parcialmente" e um respondeu que não atinge os objetivos propostos.

Sobre as açôes do PROLER e a participação do deficiente visual, observa-se mençáo a atividades de leitura e inclusão escolar nas seguintes partes do PPP: institucionalização da Educação Especial, organizada por meio do Atendimento Educacional Especializado (AEE), e projeto "Educação Inclusiva: desafios e possibilidades". Em relação à leitura, há o projeto "Biblioteca Ativa - Uma oportunidade de Criar". Não foi possível identificar se há açôes de intervenção pedagógica com alunos com deficiência visual nas práticas específicas em atividades de leitura. Identificou-se que as açôes de leitura permeiam vários projetos, mas nenhum deles especifica se há ou náo apoio e acompanhamento do PROLER.

\section{Escola 2A - U}

Escola com espaço físico entre os maiores do município. A biblioteca possui acervos em bom estado, títulos vindos do Programa Nacional do Livro Didático (PNLD), parcerias e recursos da escola. Os pais expressam satisfação em relação à nova proposta da Educação em Tempo Integral e da Educação Inclusiva.

Entre os projetos desenvolvidos estão "Leitura Familiar", "AEE", "Educação de Jovens e Adultos (EJA)/Inclusão" e "Biblioteca Ativa".

\section{Escola 3A - MMG}

A escola oferece Educação em Tempo Integral, com orientação de estudos e práticas de leitura, esporte e suas múltiplas vivências, Canto, Coral, Danças Regionais e Artesanato Popular. Oferece o AEE aos alunos com necessidades especiais e a Formação em Serviço aos professores e demais funcionários. 
Entre os projetos da escola que correspondem aos objetivos da pesquisa está "A Ciranda da Leitura, ler e escrever". Mesmo constando nas metas, não foram encontrados projetos envolvendo pessoas com deficiência nas açóes de leitura. A escola oferece AEE, mas se nota a falta de açôes mais sistematizadas na área da educação especial.

\section{Escola 4A - SC}

A partir da nova direção em 1993, a escola implementou importantes projetos. Um exemplo é "O Ensino Alternativo". A escola oferece AEE nos turnos matutino e vespertino. Sua biblioteca tem um acervo de aproximadamente 10.000 volumes. Sua equipe de profissionais é bem assessorada pela SEMEC, Casa do Educador e Formação Continuada em Serviço.

A escola desenvolve projetos ligados à família dos alunos para estimular e favorecer a parceria entre escola-família a partir de atividades que os trazem para dentro da escola, como convidar para comparecer e auxiliar na organizaçáo de eventos, abrir biblioteca, laboratório de informática e quadra de esportes para uso dos familiares, informar o desempenho dos alunos em relatórios periódicos, entre outros.

Há uma série de projetos que visam incentivar a leitura e a inclusão escolar, como: "Trabalhando com jornal dentro da escola" (Jornal Interativo); "Trabalhando com a rádio dentro da escola" (Rádio Interativa); "Agentes de Leitura”, com ênfase da participação do PROLER; "Vai uma leitura, aí?", desenvolvido pelos alunos do Fundamental e da EJA.

\section{Escola 5A - SM}

A maioria de alunos vem de bairros distantes, sendo que alguns trabalham para complementar a renda familiar. A escola percebe, por meio de bilhetes de comunicaçáo, que muitos pais são analfabetos funcionais ou semianalfabetos, pois só assinam os bilhetes, muitas vezes escritos pelos próprios alunos.

Por meio de parcerias com a SEMEC e a Fundação de Ensino Técnico Intensivo (FETI), a escola oferece oficinas que oportunizam o ingresso no primeiro emprego junto ao Departamento do Bem-Estar do Menor (PROBEM).

O acervo da biblioteca é de 27.308 livros, com espaço suficiente para atender a demanda da escola e a comunidade.

Entre os projetos desenvolvidos estão o "Espaço Biblioteca - Elo entre escola e o mundo" e a "Educação Inclusiva". Não foi possível identificar se este projeto é o mesmo do AEE, realizado nos dois turnos e atendendo os alunos público-alvo da Educação Especial.

\section{Escola 1B - AT}

A escola náo respeitou o prazo de entrega do documento para a SEMEC, não sendo possível descrever suas ações. Optou-se por mantê-la na pesquisa, considerando o critério de seleção previamente definido. 


\section{Escola 2B - ELB}

A escola atende alunos do Ensino Fundamental e EJA e, conforme a demanda, oferece o AEE. Possui sala de multimeios e biblioteca.

Para a elaboração do PPP, a gestão da escola organizou uma comissão em assembleia para coletar dados ouvindo a família e a comunidade.

A escola apresenta condiçóes de acessibilidade, como rampas de acesso com barras de segurança, sinalizaçáo tátil e visual, além de sala de AEE com recurso de TA.

Entre os projetos desenvolvidos estấo a "Hora Cívica e do Conto"; "Sala multifuncional de AEE", com atendimentos no contraturno da escolarização dos alunos e assessoramento do Departamento de Inclusão Educacional e Diversidade (DIED); "Jornal na Escola"; "A escola e a música" e "Minha escola me incentiva a ler".

\section{Escola 3B - VAT}

Fundada em 1987 a partir da nucleaçáo de sete escolas rurais. A escola possui biblioteca com espaço físico restrito. Oferece o AEE para alunos com deficiência e acentuadas dificuldades de aprendizagem. A escola costuma evitar mandar atividades extraescolares aos alunos devido ao trabalho que realizam (a maioria no campo).

A ação pedagógica na escola acontece em tempo real ao se identificar necessidades acadêmicas dos alunos; não é esperada a recuperação final para intervir em sua aprendizagem.

Entre os projetos desenvolvidos estão "Revitalização da Biblioteca" para acessibilidade e estimulação da leitura; e "Projeto Literário - Biblioteca", que trabalha um autor por mês, com exposição de trabalhos dos alunos.

\section{Escola 4B - TM}

Segundo os registros, os alunos moram longe do local, mas isso náo impede o vínculo afetivo das famílias com a instituição. A maioria dos pais é ex-aluno, facilitando o relacionamento família-escola.

Entre os projetos desenvolvidos na escola estáo o "Contar, recontar, criar e recriar é só imaginar", que incentiva a leitura e a criação de histórias, além de ser um exercício de socialização e amadurecimento psicológico; "AEE"; "Poetizando na EJA"; "Bibliodinamizando a EJA" e "Biblioteca", que estimula alunos e comunidade rural a usar a biblioteca.

\section{Escola 5B - ML}

A equipe gestora foi indicada pela SEMEC, pois a escola não apresentou candidatos ao cargo para o período 2014-2017. A escola se denomina como uma gestão democrática e participativa. Em sua infraestrutura, dispóe de bibliotecas, banheiro acessível, laboratório de informática, sala de AEE, professores em sua maioria pósgraduados, entre outros. A maioria das famílias dos alunos náo tem renda fixa e a relação direta com a escola é dificultada pela distância dos bairros atendidos. 
Alguns Programas Federais apoiam a escola para favorecer a participação efetiva do educando nas atividades escolares. São eles: o "Programa Mais Educaçáo" e o "AEE".

A seguir, a relação dos projetos desenvolvidos: "Hora da Leitura", criado a partir da análise de desempenho insatisfatório dos alunos nas avaliaçôes sobre leitura; "Escola Inclusiva: acompanhamento dos alunos - AEE implantando diretrizes e implementando sonhos"; "Biblioteca e o mundo encantado da Leitura"; "Sacola Literária”, projeto com interação família-escola, na qual, semanalmente, a Sacola Literária é enviada para leitura domiciliar; "Poetizando na EJA" e "Bibliodinamizando a EJA". Entre os Projetos Políticos Pedagógicos analisados, observou-se um movimento positivo referente às açôes a serem executadas. As açôes que envolvem estimular a leitura e a inclusão escolar foram planejadas mediante a diagnose realizada, a partir da qual puderam avaliar pontos positivos e negativos da escola. O PPP das escolas selecionadas nasceu concomitantemente ao processo de escolha de sua equipe gestora, coincidindo com o concurso e as eleiçóes pelas quais as unidades escolares estavam passando, aspecto que pode ter dado maior credibilidade à elaboração do PPP. Espera-se que uma gestáo escolar seja democrática e participativa, pense numa nova dinâmica de trabalho, queira conhecer e somar num ambiente no qual permanecerá no período de gestão e exercite uma prática coletiva como oportunidade de reflexão para mudanças de caminhos.

Verificou-se que a prática de leitura e a inclusão escolar estão presentes em todos os PPPs analisados. A partir disso, considera-se que a universalização e a qualidade da educação serão consolidadas por meio da garantia do desenvolvimento harmonioso e qualitativo da Educação Infantil, do Ensino Fundamental, da EJA e da Educação Inclusiva. Apesar disso, é importante ressaltar que, apesar de várias açóes referentes à leitura estarem expostas no documento, ainda assim não foi possível identificar trabalhos e/ou estratégias de leitura que mencionem parcerias com o PROLER.

Em apenas uma escola $(2 \mathrm{~A}-\mathrm{U})$ o PROLER foi realmente citado. Já no que se refere à participação do deficiente visual, não houve nenhum documento que descrevesse claramente as açóes que exemplifiquem o que foi buscado nessa pesquisa, cujo objetivo, além de identificar açóes, é torná-las passíveis de serem executadas a partir do conhecimento das peculiaridades da deficiência visual para promover açóes simples e eficazes que favoreçam a participação dessa pessoa nos diversos ambientes, de acordo com a sua necessidade.

\section{Participação do dificiente visual nas atividades de leitura.}

Para a promoção do desenvolvimento de pessoas com deficiência visual nas áreas de avaliação funcional da visão, intervenção precoce e sensorial, atividades de vida diária, orientação e mobilidade, Uberaba conta com uma Instituição de Ensino Especializado, denominada Instituto de Cegos do Brasil Central (ICBC), sede do Núcleo de Apoio Pedagógico e Produção Braille (NAPPB). O ICBC atende pessoas da comunidade e municípios circunvizinhos, presta assessoria às escolas de Uberaba, é responsável pela capacitação dos profissionais na área da deficiência visual e 
adaptaçáo de material para que o aluno possa acompanhar seus estudos em Braile ou tipo ampliado. O município arca com a cessão de profissionais e com a compra de materiais de consumo.

Há também em Uberaba um Centro de Apoio Pedagógico às Pessoas com Deficiência Visual (CAP/Estadual). Além de atender os municípios de sua abrangência, atende as Escolas Estaduais e Municipais em assessoramentos, capacitaçóes aos profissionais da educação, adaptaçáo de materiais em Braile e do tipo ampliado, escolarização, atendimentos especializados ao deficiente visual/família e reabilitaçáo.

Uberaba conta ainda com o DIED, que presta assessoria nas salas de AEE. A equipe do DIED conta com apenas um profissional responsável por ir às escolas, quando solicitado, para identificar dificuldades visuais funcionais, orientar e encaminhar o aluno com suspeita de baixa visão ao oftalmologista e, posteriormente, aos serviços do ICBC. O DIED é responsável por orientar a escola, relatando em um parecer psicológico sobre as informaçóes coletadas para auxiliar a equipe escolar nas atividades com o aluno. Após o encaminhamento realizado, a escola continua recebendo orientaçóes do DIED por assessoramentos nas salas de AEE e/ou cursos de capacitação.

É preciso identificar como o escolar enxerga e, para tanto, algumas estratégias são realizadas. A Avaliação Funcional da Visão estipula um planejamento para estimular o resíduo visual que a pessoa apresenta. Esse trabalho é denominado de Estimulaçáo Visual, que visa adquirir uma maior consciência visual. A pessoa não melhora sua acuidade visual, mas aprende a utilizar melhor o seu resíduo, favorecendo uma maior autonomia nas diversas atividades que queira exercer. Nessa mesma avaliação, pode ser identificada a necessidade do uso de lupas para auxiliar nas atividades diárias. É identificado ainda se há necessidade de ampliação de seu material e se há alguma adaptação arquitetônica que possa favorecê-lo nas atividades de leitura e escrita. Quanto ao aluno cego, as aulas de Braile, orientação e mobilidade, informática e atividades de vida diária serão essenciais para um bom desempenho. Percebe-se um crescente número de editoras que disponibilizam o material, antes comercializado somente impresso, compatível para ser explorado por meio de recursos de áudio, em Braile, ampliado e com duas escritas (tinta e Braile).

\section{Considerações finais}

Segundo a Constituição Federal de 1988 (BRASIL, 1988), todos são iguais perante a lei, afirmação que não assegura igualdade de fato, sendo muitas as desigualdades. Sendo assim, compreende-se a deficiência como uma construçáo social do homem e sua condiçáo como um permanente resultado de um processo no qual cada envolvido tem como contribuir.

A escola é considerada um campo fecundo nas relaçóes humanas, nas práticas de ensino e na construçáo de valores e normas. Mesmo assim, é perceptível que existem grandes dificuldades enfrentadas pelo deficiente. A educação não é um fato isolado. Ela é parte de uma engrenagem que deve ser harmonizada por componentes como a família, a sociedade e a comunidade escolar. A escola é apenas mais um dos fa- 
tores nessa soma de elementos que permitem ao aluno ser chamado de cidadáo e que provoquem mudanças de comportamentos. Percebe-se que muitos são os caminhos a serem percorridos para que a pessoa com deficiência participe ativamente do processo de inclusão nas escolas. Mesmo com os avanços gradativos da sociedade, ainda há muito a contribuir na tentativa de valorizar e oportunizar a real participaçáo desse grupo de pessoas que por longos anos ficou à margem da sociedade, lembrando que as mudanças náo ocorrem rapidamente, uma vez que implicam questôes políticas, científicas, pedagógicas, administrativas e financeiras.

A partir da leitura dos Projetos Políticos Pedagógicos selecionados para o artigo constatou-se que sáo muitas as açóes desenvolvidas. Uberaba vem alcançando metas perceptíveis ao se observar o crescimento do número de matrículas de crianças com deficiência nas escolas, além do número expressivo de participantes nos encontros regionais do PROLER. Apesar disso, percebe-se que as açóes desenvolvidas são isoladas. Parece não haver diálogo entre as escolas analisadas e os Departamentos para que, de fato, aconteça um maior envolvimento nos projetos e, assim, um fortalecimento nas açóes de leitura e participação do deficiente. Constatou-se que houve uma diretriz do que precisaria ser descrito nos documentos das escolas, porém sem identidade. No que se refere à inclusão, não foi possível perceber a concepção do Comitê do PROLER. Também não foi possível notar diferenças regionais, de clientela assistida e de perfil dos funcionários nos PPPs das escolas analisadas.

Acredita-se que esta pesquisa poderá contribuir no convite para refletir sobre qual é o verdadeiro sentido do PPP para fortalecer as açóes e para a melhoria da qualidade do ensino, além da importância de a escola estar realmente aberta às diferenças e com um diálogo mais transparente. A pesquisa aponta caminhos que podem favorecer o trabalho da equipe pedagógica para o bom desenvolvimento do aluno com deficiência. Reconhece-se a necessidade de continuidade da temática por sua importância em prol de uma sociedade mais justa, dinâmica e humana, a fim de que a população, os gestores e demais órgáos públicos respeitem as diferenças e compreendam as reais necessidades da pessoa com deficiência, garantindo sua autonomia nos diversos espaços da sociedade, distanciando-se dos pré-julgamentos sobre sua capacidade e do assistencialismo ainda presente nas açóes que envolvem o trabalho com o deficiente.

\section{Referências}

BERSCH, R.; TONOLLI, J. C. Tecnologia Assistiva. 2006. Disponível em: <http://www.assistiva.com.br/>. Acesso em: 03 mai. 2014.

BRASIL. Constituiçấo (1988). Constituiçấo da República Federativa do Brasil. Brasília, DF: Senado Federal: Centro Gráfico, 1988. 292 p.

Lei 10753/2003. Institui a Política Nacional do Livro. Disponível em: <http://www.planalto.gov.br/ccivil_03/ leis/2003/L10.753.htm. >. Acesso em: 03 maio 2014.

Ministério da Educação. Secretaria de Educação Especial. Grafia Braille para a Língua Portuguesa. Secretaria de Educação Especial. Brasília: SEESP. 106p. 2006.

Plano Nacional do Livro e da Leitura - PNLL. MEC. Brasília, 2006.

Senado Federal. Lei de Diretrizes e Bases da Educaçáo Nacional: no 9394/96. Brasília: 1996.

CARVALHO, R. E. Educação inclusiva com os pingos nos “is”. 4. ed. Porto Alegre: Mediação, 2004. 176p. 
FERRARI, C. E. Fomento ao uso de tecnologias assistivas por pessoas cegas e com deficiência visual na grande Sáo Paulo. Dissertação (Mestrado em Administração) - Universidade Municipal de São Caetano do Sul, São Caetano do Sul, 2008.

GODOFFREDO, V. F. S. Fundamentos da Educação Especial. 1. ed. Rio de Janeiro: UNIRIO/CEAD, 2007. $158 \mathrm{p}$.

JAMBEIRO, O.; BORGES, J.; BARROS, S. Políticas Públicas para o livro e a leitura e sua influência na indústria editorial de Salvador. Link em Revista, v. 2, p. 178-191, 2006. Disponível em: <http://revista.ibict.br/ liinc/index./>. Acesso em: 16 set. 2010.

LEITÃO, J. C; FERNANDES, C. T. Inclusão escolar de sujeitos com deficiência visual na rede regular de ensino brasileira: revisão sistêmica. Linhas críticas, Brasília, DF, v. 17, n. 33, p.273-289, maio/ago. 2011.

LIBÂNEO, J. C. Organizaçáo e Gestáo da escola - Teoria e prática. 4. ed. Goiânia: Editora Alternativa, 2001. 259p.

MANTOAN. M. T. E. Inclusão escolar: O que é? Por quê? Como fazer? 1. ed. São Paulo: Moderna, 2006. 96p. MINISTÉRIO DA EDUCAÇÃO (MEC). AEE - Deficiência Visual, 2007. Disponível em <mec.gov.br/seesp/ arquivos/pdf/aee_dv.pdf>. Acesso em: 14 ago. 2015.

NUNES, J. C. M. Leitura: Experiência Sócio-Cultural-educativa. In: SEED-MEC. Viva a Leitura: Iniciativas Formais e Informais. Brasília: SEED-MEC, 2007. p. 13-17.

SÁ, E. D.; CAMPOS, I. M.; SILVA, M. B. C. Atendimento Educacional Especializado - Deficiência Visual. São Paulo: MEC/SEESP, 2007. 54p.

VASCONCELLOS, C. S. Planejamento: Projeto de Ensino-Aprendizagem e Projeto Político Pedagógico. 14. ed. São Paulo: Liberdad, 2000.

VEIGA, I. P. A. Escola: Espaço do Projeto político-pedagógico. Campinas: Papirus, 1998. 200p.

\section{Correspondência}

Dulceana Pereira - Universidade de Uberaba. R. dos Expedicionários, Vila Ferreira, Santa Adélia. CEP: 15950-000. Uberaba, Minas Gerais,Brasil.

E-mail: dulceanapereira@gmail.com - lucianabeatrizcarvalho@yahoo.com.br

Correspondência em 02 de maio de 2016

Final em 31 de janeiro de 2017 
